Ianina Harari, Evolución de las condiciones de trabajo en la industria metalúrgica argentina. Un análisis a partir de los convenios colectivos de trabajo entre 1948 y 1994 / Evolution of the working conditions in the steel industry in Argentina. An analysis based on the collective labor agreements between 1948 and 1994, Revista Izquierdas, 27, abril 2016, ISSN 0718-5049, pp. 87-104

\title{
Evolución de las condiciones de trabajo en la industria metalúrgica argentina. Un análisis a partir de los convenios colectivos de trabajo entre 1948 y 1994
}

Evolution of the working conditions in the steel industry in Argentina. An analysis based on the collective labor agreements between 1948 and 1994

\author{
Ianina Harari*
}

\footnotetext{
* Argentina. Dra. en Historia, docente de Facultad de Filosofía y Letras de la Universidad de Buenos aires e Investigadora Asistente CEIL-CONICET, ianinaharari@yahoo.com.ar
} 

convenios colectivos de trabajo entre 1948 y 1994 / Evolution of the working conditions in the steel industry in Argentina. An analysis based on the collective labor agreements between 1948 and 1994, Revista Izquierdas, 27, abril 2016, ISSN 0718-5049, pp. 87-104

\section{Resumen:}

En este artículo analizamos los convenios colectivos firmados por la Unión Obrera Metalúrgica, el gremio que representa a los trabajadores del sector en Argentina, entre 1948 y 1994. Nos centraremos en las modificaciones de las principales cláusulas como las categorías, las pautas de productividad o las licencias. Creemos que este análisis nos permite evaluar la evolución de los derechos adquiridos o perdidos por los obreros, así como las demandas que impone el sector empresarial en cada etapa.

Palabras clave: Convenios Colectivos, Industria metalúrgica, Argentina, Clase Obrera

Recibido: 10 noviembre 2015

Aceptado: 23 enero 2016

\begin{abstract}
:
In this paper we analyze the collective bargaining agreements signed by the Metal Workers Union, the union representing the workers of this economic field in Argentina, between 1948 and 1994. We focus on the changes of the main clauses, such as the categories, patterns of productivity or licenses. We believe that this analysis allows us to evaluate the evolution of rights acquired or lost by the workers and the demands imposed by the Employers at every stage.
\end{abstract}

Keywords: Collective bargaining agreements, Metallurgy, Argentine, Working Class

\section{Introducción}

En la Argentina, desde 1953, rige la ley de convenios colectivos 14.250, que regula las negociaciones colectivas entre los sindicatos obreros y las patronales. Existían antecedentes normativos, como el Decreto Ley 23.852 de 1945 , que autorizaba a los sindicatos con personería jurídica otorgada por el estado a llevar adelante las negociaciones colectivas, y la negociación colectiva es pre existente a esta norma ${ }^{1}$. Como señala Levaggi ${ }^{2}$, antes de la sanción de la Ley 14.250, las convenciones colectivas eran avaladas por la jurisprudencia, aunque en muchas ocasiones se les negaba la validez erga omnes. La Ley 14.250, regula específicamente la firma de convenios colectivos. Esta norma implicó el reconocimiento legal de la vigencia de los convenios colectivos, donde se plasman las condiciones laborales y salariales pactadas entra las partes, y avaladas por el estado, así como la posibilidad de renegociar los mismos con cierta periodicidad. Así, el resultado de las negociaciones

\footnotetext{
${ }^{1}$ Ricardo Gaudio y Pilone Jorge, "El desarrollo de la negociación colectiva durante la etapa de modernización industrial en la Argentina. 1935-1943", Desarrollo Económico, Vol. 23, n 90, julio-septiembre de 1983, 255286.

2 Abelardo Levaggi, "Historia del derecho argentino del trabajo (1800-2000)", Iushistoria, Buenos Aires, Universidad del Salvador, $\mathrm{n}^{\circ}$ 3, setiembre de 2006.
} 
Ianina Harari, Evolución de las condiciones de trabajo en la industria metalúrgica argentina. Un análisis a partir de los convenios colectivos de trabajo entre 1948 y 1994 / Evolution of the working conditions in the steel industry in Argentina. An analysis based on the collective labor agreements between 1948 and 1994, Revista Izquierdas, 27, abril 2016, ISSN 0718-5049, pp. 87-104

paritarias quedan plasmadas en un documento con carácter legal que obliga a las partes a cumplirlas o a reclamar su cumplimiento.

El análisis de los convenios colectivos en el largo plazo permite una aproximación a los cambios en las condiciones de trabajo. De esta manera, los convenios resultan una fuente importante para rastrear los períodos en que esas condiciones son modificadas en favor de una u otra de las partes firmantes: obreros y empresarios. En ese sentido, aquello que se conoció como "flexibilidad laboral" durante la década de los '90, y que se plasmó en la legislación laboral de esa década, tiene sus antecedentes en algunas cláusulas ya presentes en los convenios colectivos. Creemos que es posible rastrear, a través de estos documentos, los momentos de avance y retroceso de la flexibilidad laboral, entendida como un momento de avance de la ofensiva empresaria dirigida a desmantelar las condiciones de trabajo conquistadas por la clase obrera.

El estudio de los CCT en el período cobra relevancia a la luz del problema sobre los momentos históricos en que se produce una avanzada sobre los derechos obreros conquistados. En ese sentido, en la Argentina se ha debatido este problema para dos períodos. El primero es la década del '60, luego de las luchas obreras que siguieron al derrocamiento del gobierno de Perón en 1955. Las demandas empresariales en torno a las conquistas obreras logradas bajo el peronismo se expresaron en dos cuestiones centrales: la racionalización y el poder de los sindicatos en los lugares de trabajo. ${ }^{3}$ Estos aspectos habían sido planteados durante el gobierno peronista, lo cual se vio plasmado con mayor énfasis en el congreso de la productividad, donde el empresariado no consiguió una definición favorable. ${ }^{4}$ El problema que se ha debatido es si a lo largo de la década del '60 el sector empresario logró imponer algunas de sus demandas. James ha planteado a partir del análisis del convenio metalúrgico de 1960, que la patronal del sector habría conseguido avanzar sobre la racionalización y la implementación de pautas de productividad. En cambio, Schneider, en base a la misma fuente, considera lo opuesto: que la patronal no habría logrado imponer tales demandas. Ambos se centran el artículo que refiere a la productividad y que analizaremos más adelante. Sin embargo, creemos que el análisis de la totalidad de las cláusulas de los convenios en un período mayor, nos permite analizar el convenio de 1960 en el lugar que ocupa dentro de la secuencia histórica de los cambios en las normas que rigen las condiciones de trabajo en la industria.

El segundo período, y el más analizado, ha sido la década de los '90. Es usual encontrar en la bibliografía la referencia a la década del '90 como el momento en que se impone la flexibilidad laboral, en tanto se revierten algunas pautas laborales favorables a los obreros, como el sistema de categorías, de la jornada laboral y de las formas salariales y contractuales. ${ }^{5}$ Creemos que una mirada de largo plazo permitirá matizar esta visión, entendiendo que la flexibilización de las condiciones laborales se ha producido también en

\footnotetext{
${ }^{3}$ Daniel James, Resistencia e Integración: el peronismo y la clase trabajadora argentina: 1946-1976, Buenos Aires, Sudamericana, 1990, 188-198.

${ }^{4}$ Rafel Bitrán, El congreso de la Productividad, Buenos Aires, El bloque editorial, 1994.

5 Enrique De la Garza Toledo, "La flexibilidad del trabajo en América Latina”, Enrique De la Garza Toledo, Tratado Latinoamericanos de Sociología del Trabajo, México, Siglo XXI, 2000, 148-177.
} 

convenios colectivos de trabajo entre 1948 y 1994 / Evolution of the working conditions in the steel industry in Argentina. An analysis based on the collective labor agreements between 1948 and 1994, Revista Izquierdas, 27, abril 2016, ISSN 0718-5049, pp. 87-104

momentos anteriores a la oleada neoliberal. Específicamente, se observa que sobre fines del gobierno peronista se produce una ofensiva que fracasa en ese momento, pero se logra imponer en la década del '60. A su vez, en la primera mitad de los '70 la clase obrera logra revertir en parte esa normativa. La década del '90 será, finalmente, el período donde se consiga avanzar con una legislación laboral más acorde a los intereses empresariales.

En este trabajo nos proponemos analizar la evolución de los convenios colectivos que rigieron para los obreros metalúrgicos en la Argentina entre 1948 y 1975. La Unión Obrera Metalúrgica (UOM) ha sido uno de los gremios con mayor peso en el mapa sindical argentino. Este gremio ostentaba una gran capacidad de negociación en comparación con otros sindicatos. En ese sentido, la rama metalúrgica ha sido una de las ramas en las cuales los obreros empleados en blanco gozaban de ciertos beneficios que estaban vedados a trabajadores de otros sectores económicos. ${ }^{6}$

Para llevar a cabo el análisis de los vaivenes de la normativa que rige el trabajo de los obreros metalúrgicos, nos centramos en los principales aspectos relativos tanto a las condiciones de trabajo como a la actividad gremial en los lugares de trabajo y las modificaciones que sufrieron de un convenio a otro. Nuestro análisis parte de 1948, año en que la UOM firma el primer convenio colectivo por rama, y llega hasta 1994. Comenzaremos por un análisis de los principales artículos de los convenios para luego intentar establecer una periodización de la negociación colectiva en el sector.

\section{Categorías y condiciones de trabajo}

Las categorías en los establecimientos metalúrgicos se establecían por rama de industria de acuerdo a las diversas tareas que se desarrollaban allí. En general, abarcaban desde peón hasta Oficial, pasando por operario, operario calificado, operario especializado y medio oficial. Además, se establecían los conocimientos que correspondían a cada oficio.

En cuanto al ascenso de categoría se establecía que la prueba podía tomarse dos veces por año, pero sólo se podía ocupar el nuevo cargo si existían vacantes ${ }^{7}$. En 1951 se establece que sólo se puede solicitar rendir la prueba en los meses de abril y octubre y se restringe la posibilidad de rendirla a una vez por año ${ }^{8}$. En 1960 se establece, para los medios oficiales que rindiesen la prueba sin poder ocupar el nuevo cargo, un adicional ${ }^{9}$.

\footnotetext{
${ }^{6}$ Marina Kabat, Ianina Harari, Julia Egan, Rocío Fernández, Sebastián Cominiello, Roberto Muñoz, Ezequiel Murmis, "Avances y retrocesos de la flexibilidad laboral en la Argentina. Aportes para una comparación de las trayectorias históricas de distintas ramas de actividad", Mundos do Trabalho, vol. 6, n 12, Brasil, juliodiciembre de 2014.

${ }^{7}$ Convención Colectiva no 22/48, Ministerio de Trabajo y Previsión, Dirección Nacional de Trabajo y Acción Social Directa, Registro General de Convenios y Laudos, Buenos Aires, 2 de marzo de 1948, art. 10

${ }^{8}$ Convención Colectiva de Trabajo n ${ }^{\circ}$ 97/51, Ministerio de Trabajo y Previsión, Dirección Nacional de Trabajo y Acción Social Directa, Registro General de Convenios y Laudos, 1951, art. 12

${ }^{9}$ Convención Colectiva de Trabajo n 55/60, Ministerio de Trabajo y Seguridad Social, 11 de julio de 1960, art. 12
} 

convenios colectivos de trabajo entre 1948 y 1994 / Evolution of the working conditions in the steel industry in Argentina. An analysis based on the collective labor agreements between 1948 and 1994, Revista Izquierdas, 27, abril 2016, ISSN 0718-5049, pp. 87-104

Asimismo, desde el '48, se establece que las vacantes producidas dentro del establecimiento deben ser llenadas con preferencia por obreros de la categoría inferior. ${ }^{10}$ Un elemento que se mantiene constante a lo largo de los distintos convenios es la prerrogativa en torno a las tareas a las que se destina al personal. En este sentido, aquello que hoy denominaríamos polivalencia, se encontraba limitado por el hecho de que la empresa debía respetar las categorías y las tareas de cada obrero o, en su defecto, realizar un pago adicional. Sin embargo, la misma no era prohibida sino aceptada como un hecho consumado al que se "penaba".

Por ejemplo, los obreros que fuesen destinados a tareas de una categoría superior a la que poseían, debían cobrar la diferencia salarial correspondiente durante el lapso en que fueran ejecutadas. En caso de que el obrero hubiera trabajado 550 horas en esas tareas, se le debería pagar en forma permanente por la categoría superior. ${ }^{11}$

En el convenio de 1951 se agrega un artículo ${ }^{12}$ por el cual los empleados que debían realizar tareas de una categoría inferior mantenían su categoría.

Ningún empleado podrá ser destinado a realizar trabajos que le signifiquen un menoscabo moral. Los empleados que circunstancialmente tengan que realizar tareas inherentes a una categoría inferior a la que realizaban, no podrán sufrir modificaciones en su Categoría. Los empleados que en su desempeño habitual desarrollan actividades de distintas categorías podrán ser destinados a trabajos de su habitualidad. Quienes tengan que desarrollar tareas que le signifiquen un mayor esfuerzo físico que el habitual, contarán con la cooperación del personal adecuado. ${ }^{13}$

También ese año se agrega que un empleado calificado realice tareas de otro grupo, se le debía pagar un adicional. Los horarios de descanso fueron estipulados desde el convenio de 1948:

Todos los obreros cuando trabajan en turnos diurnos continuados de 8 horas o mas o nocturnas de 7 o más horas consecutivas gozarán como máximo de un descanso de 20 minutos para merendar, las mimas franquicias se le otorgará al personal femenino que trabaje en turnos continuados de 7 horas. Queda establecido que este descanso no puede ser descontado ni recargado de la jornada de labor, sin mengua de sus salarios. Queda asimismo establecido que el presente artículo no puede ser causa para la disminución de descansos mayores que actualmente estuvieran gozando los obreros. ${ }^{14}$

\footnotetext{
${ }^{10}$ Convención Colectiva de Trabajo no $22 / 48$, Op. Cit., art. 14

${ }^{11} \mathrm{Ibid}$, art. 11

${ }^{12}$ Convención Colectiva de Trabajo ${ }^{\circ}$ 97/51, Op. Cit., art. 56

${ }^{13} \mathrm{Ibid}$, art. 42

${ }^{14}$ Convención Colectiva de Trabajo n ${ }^{\circ}$ 22/48, Op. Cit., art. 26
} 

convenios colectivos de trabajo entre 1948 y 1994 / Evolution of the working conditions in the steel industry in Argentina. An analysis based on the collective labor agreements between 1948 and 1994, Revista Izquierdas, 27, abril 2016, ISSN 0718-5049, pp. 87-104

Este descanso será ampliado a media hora en el convenio firmado en $1975^{15}$. Para la realización de horas extras debía solicitarse la conformidad del sindicato ${ }^{16}$. En el convenio de 1975 se establecen los porcentajes para el pago de las mismas ${ }^{17}$. Lo curioso acerca del horario de trabajo es que en el convenio de 1960 aparece un artículo referido a la obligatoriedad de cumplimentar la jornada de trabajo: "La jornada de trabajo será cumplida íntegramente, respetando en su totalidad la hora de inicio y finalización"18.

La inclusión de esta cláusula puede deberse a la necesidad de imponer una mayor disciplina laboral por parte de las empresas, la cual, como veremos, aparece reflejada en el convenio.

En cuanto al trabajo insalubre, se establece un adicional para los obreros que trabajen en ese tipo de tareas y un horario reducido de 6 horas ${ }^{19}$. Además, el personal ocupado en estas secciones debía recibir un litro de leche diaria ${ }^{20}$, que permite prevenir enfermedades laborales propias de trabajos con metales, como el saturnismo. En 1951 se establece que sólo podrá levantarse la insalubridad de la tarea mediante un pronunciamiento de la Dirección General de Higiene y Seguridad del Trabajo, lo cual implica una instancia de salvaguarda ante posibles arbitrariedades por parte de la empresa. También se establece un adicional del $20 \%$ para tareas peligrosas y aquellas realizadas en altas temperaturas. ${ }^{21}$ Para los accidentes de trabajo, en 1948 se estableció que además del medio jornal que le correspondía cobrar al obrero en los días de trabajo perdido, se debía abonar un suplemento hasta completar el importe del salario correspondiente. ${ }^{22}$ En 1975 , se agregara un párrafo en torno a la gravedad del accidente:

Pasado el término de un año, la incapacidad se considerará como permanente a los efectos de la indemnización. Los salarios pagados de acuerdo con lo previsto en el primer párrafo del presente artículo, en ningún caso podrán descontarse de la indemnización que pudiera corresponderle. $^{23}$

Sobre las herramientas utilizadas, el convenio de 1948 establece que los obreros que requerían en sus tareas el uso de calibre, debían contar con este instrumento así como metro, cuatro compases y reglas de acero. Por el uso de estos elementos, la empresa debía abonarles una amortización. ${ }^{24}$ Cabe aclarar que estos elementos eran costosos, en especial el calibre, a su vez que imprescindibles para la realización de ciertas tareas de medición de

${ }^{15}$ Convención Colectiva de Trabajo no 260/75, Ministerio de Trabajo, Buenos Aires, 24 de julio de 1975, art. 27

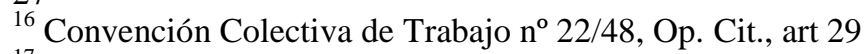

${ }^{17}$ Convención Colectiva de Trabajo n ${ }^{\circ}$ 260/75, Op. Cit., Art. 23

${ }^{18}$ Convención Colectiva de Trabajo n ${ }^{\circ} 55 / 60$, Op. Cit., art. 85

${ }^{19}$ Convención Colectiva de Trabajo no 22/48, Op. Cit., art. 20

${ }^{20}$ Ibid, art. 21

${ }^{21}$ Ibid, art. 24 y 25

${ }^{22}$ Ibid, art 30

${ }^{23}$ Convención Colectiva de Trabajo no 260/75, Op. Cit., art. 36

${ }^{24}$ Convención Colectiva de Trabajo no $22 / 48$, Op. Cit., art. 17 

convenios colectivos de trabajo entre 1948 y 1994 / Evolution of the working conditions in the steel industry in Argentina. An analysis based on the collective labor agreements between 1948 and 1994, Revista Izquierdas, 27, abril 2016, ISSN 0718-5049, pp. 87-104

gran precisión, por ejemplo para el control de las piezas. Para 1975 esta cláusula es desterrada del convenio y reemplazada por una que obliga a la empresa a proveer a los trabajadores de las herramientas:

La empresa debe proveer a los trabajadores de las herramientas, instrumentos de medición, útiles y elementos necesarios para desempeñar sus respectivas tareas; b) La reposición de esos elementos, cuando el desgaste por el uso normal y habitual la haga necesario, estará, a cargo del empleador; c) Cuando se carezca del instrumental requerido o por incumplimiento de lo indicado en el inciso b) precedente, se registraran deficiencias técnicas en los trabajos encomendados, el trabajador quedará eximido de responsabilidad. ${ }^{25}$

\section{El goce de licencias}

La reglamentación en torno a las licencias parece endurecerse hacia el convenio de 1960. En 1951 se establece que el obrero que se ausentara por enfermedad mantenía su derecho al puesto, pero sin gozar de salario a excepción de las asignaciones familiares, sin que esto modificara su relación contractual, como lo establecía la ley 11.729. ${ }^{26}$ Ahora bien, en 1960 se imponen una serie de requisitos para gozar de los beneficios de dicha ley. Es decir que el incumplimiento de alguno de ellos podría implicar la pérdida del salario correspondiente a esos días o, incluso, del puesto de trabajo. Así, en este convenio se establece que el obrero que faltase por enfermedad o accidente inculpables, debía comunicarlo a la empresa en el lapso de la primera mitad de su jornada laboral sea por telegrama, por aviso directo del mismo interesado en el establecimiento, por cualquier persona que avisara en su nombre en el establecimiento o por teléfono, en los casos en que se aplique este sistema. En caso del personal que trabajaba en el turno nocturno y no contara con medios para comunicarse con la empresa, debía informar dentro de las primeras horas del turno siguiente. A su vez, la empresa tenía derecho a verificar el estado de salud por medio de su servicio médico y el trabajador la obligación de facilitar dicha verificación. En caso que el empleador no realizara el chequeo, el empleador debía presentar un certificado médico. ${ }^{27}$

En 1975, este artículo fue modificado en términos menos perjudiciales para el trabajador. Por un lado, se establece un horario para la verificación que va de las 7 a las 21 hs. Por otro lado, se agrega una cláusula que deja abierta la posibilidad de no comunicar a la empresa sobre la situación:

La omisión injustificada de la comunicación de la enfermedad o accidente será considerada como acto de indisciplina, pero no alterará su derecho al cobro de las remuneraciones respectivas si su existencia,

\footnotetext{
${ }^{25}$ Convención Colectiva de Trabajo n ${ }^{\circ}$ 260/75, Op. Cit., art. 38

${ }^{26}$ Convención Colectiva de Trabajo no 97/51, Op. Cit., art. 26.

${ }^{27}$ Convención Colectiva de Trabajo n ${ }^{\circ} 55 / 60$, Op. Cit., art. 81
} 

convenios colectivos de trabajo entre 1948 y 1994 / Evolution of the working conditions in the steel industry in Argentina. An analysis based on the collective labor agreements between 1948 and 1994, Revista Izquierdas, 27, abril 2016, ISSN 0718-5049, pp. 87-104

teniendo en consideración su carácter y gravedad, resultase inequívocamente acreditada mediante certificado médico extendido por facultativo habilitado. ${ }^{28}$

En lo que refiere a la enfermedad de un familiar, ya en 1951 se reglamenta que el patrón tiene derecho a verificar la misma. En 1960 se puso un límite a este tipo de licencias. Se estableció que sólo podían tomarse 2 o 3 meses por año por este motivo según si la antigüedad fuera menor o mayor a 10 años respectivamente. El año se contabilizaba a partir del inicio de la licencia.

Asimismo, en 1960 se endurece el artículo en torno al pedido de licencias sin goce de sueldo que el convenio de 1951 deja a consideración de la patronal. ${ }^{29}$ En el convenio del '60 la misma debía ser solicitada con un mínimo de 10 días de antelación. Nuevamente, será en 1975 cuando se flexibilice este artículo reduciendo el plazo a 3 días y aclarando que se hará salvedad de circunstancias especiales, lo cual deja abierta la posibilidad de sortear esta exigencia. También en 1960 se agrega un artículo en torno a faltas injustificadas: "El obrero que se ausente por causas imprevistas no contempladas en el convenio deberá notificar en las primeras horas y hasta la mitad de su jornada laboral, sin que esto le de derecho a percibir el sueldo" 30 .

En 1966 se instaura el 7 de septiembre como el Día del Metalúrgico, el cual es declarado feriado. Sobre la década del '70 también se agregaran otros beneficios. En el convenio de 1970 se agrega una licencia ordinaria de 12 días corridos con menos de 5 años de antigüedad, siguiendo la Ley $18.388 .^{31}$ En 1975 se agrega, además, el feriado del $1^{\circ}$ de enero como obligatorio y se otorga un día de licencia por mudanza

\section{Productividad y destajo}

La cuestión de la productividad fue una de las mayores preocupaciones empresariales, al menos desde el segundo gobierno peronista, cuyo epicentro fue el Congreso de la Productividad y el Bienestar Social. ${ }^{32}$ Ligado a esta problemática se encontraba el pago de salarios a destajo $^{33}$. Si bien el trabajo a destajo no aparece reglamentado, sí figura como una situación de hecho cuando en el convenio de 1951, al establecer los adicionales por trabajo

\footnotetext{
${ }^{28}$ Convención Colectiva de Trabajo no 260/75, Op. Cit., art. 35

${ }^{29}$ Convención Colectiva de Trabajo n ${ }^{\circ} 97 / 51$, Op. Cit., art. 63

${ }^{30}$ Convención Colectiva de Trabajo n ${ }^{\circ} 55 / 60$, Op. Cit., art. 84

${ }^{31}$ Convención Colectiva de Trabajo n ${ }^{\circ}$ 97/70, Ministerio de Economía y Trabajo, Secretaría de Estado de Trabajo, 18 de marzo de 1970, art. 18

32 Bitrán, op. cit., Marcos Giménez Zapiola y Carlos Leguisamon, "La concertación en 1955. El Congreso de la Productividad". Juan Carlos Torre (comp.), La formación del sindicalismo peronista, Buenos Aires, Legasa, 1980.

${ }^{33}$ Con el término "destajo" nos referimos a la forma salarial que se mide por pieza lo cual implica la sujeción, ya sea total o parcial, del salario a la intensidad del trabajo.
} 

convenios colectivos de trabajo entre 1948 y 1994 / Evolution of the working conditions in the steel industry in Argentina. An analysis based on the collective labor agreements between 1948 and 1994, Revista Izquierdas, 27, abril 2016, ISSN 0718-5049, pp. 87-104

insalubre se discrimina a aquellos obreros que fuesen remunerados a destajo, con primas o "cualquier otro sistema análogo" 34 .

A pesar de ser un punto conflictivo y parte de los reclamos obreros ${ }^{35}$, en ningún momento el convenio se expide en contra de esta forma de remuneración. Por el contrario se puede rastrear el consentimiento que el sindicato presta a este método ya en el convenio salarial que se firma luego de la huelga del '54. ${ }^{36}$ Luego de la huelga de 1959, en donde la patronal vuelve a insistir en que los aumentos salariales se acompañen de un incremento de la productividad, lo cual es aceptado por el gremio. Efectivamente, el pago por productividad parecía existir en la industria. Un ejemplo lo encontramos en la empresa Siam Di Tella Automotores. El directorio de la firma se quejaba de la huelga de 1959 por lo que ellos veían como "reclamaciones injustas de los obreros" acerca del sistema de premios instituido por la empresa. ${ }^{37}$ Finalmente, el conflicto se resolvió incrementando los premios sin incrementar la productividad en compensación. ${ }^{38}$

Ahora bien, en el convenio de 1960, aparece un artículo que instituye la aceptación del pago a destajo, o al menos su no cuestionamiento, y el compromiso de la UOM a no tomar ninguna medida en su contra.

Los sistemas de premios o cualquier otra forma de incentivación no constituyen materia propia de la convención colectiva. Sin prejuicio de ello, déjese aclarado en forma expresa que la Unión Obrera Metalúrgica de la República Argentina y/o sus delegaciones de los distintos establecimientos no podrán oponerse a la revisión de los sistemas vigentes cuando la incidencia que en ellos puedan ejercer los salarios, los métodos de trabajo, la renovación o modernización de las maquinarias y/o cambios técnicos como así también la variación en la calidad de la materia prima, los haga anti económicos o desnaturalice el superior propósito de incentivar razonablemente la producción que debe presidirlos. ${ }^{39}$

Este artículo vuelve a aparecer en los convenios firmado durante la década del '60 y sólo desaparece en el convenio del '75, cuando la reactivación de la lucha obrera implicó una presión en ese sentido. Sin embargo, en ese mismo convenio, cuando se detallan las categorías en la rama de empleados, figura como tarea propia del personal de control de

\footnotetext{
${ }_{35}^{34}$ Convención Colectiva de Trabajo ${ }^{\circ}$ 97/51, Op. Cit., art. 30

35 Silvia Simonassi y Laura Badaloni, "Prácticas sociales y políticas estatales en dos coyunturas de conflictividad laboral: estado, industriales y trabajadores metalúrgicos durante el primer peronismo", Segundas Jornadas de Historia Regional Comparada, 2005; Marcos Schiavi, "Ser o no ser Clase obrera y gobierno peronista: el caso de la huelga metalúrgica de 1954", Theomai, n 18, 2008.

${ }_{37}^{36}$ Convención Colectiva de Trabajo $n^{\circ}$ 97/51, Op. Cit., art. 30.

${ }^{37}$ Siam Di Tella: Memoria y Balance General del ejercicio vencido al 30/4/1959, en Boletín de la Bolsa de Comercio no 2846, 23/11/1959

${ }^{38}$ Boletín de la Bolsa de Comercio no 2847, 30/11/1959, pág. 2393

${ }^{39}$ Convención Colectiva de Trabajo no ${ }^{\circ} 55 / 60$, Op. Cit., art. 83
} 

convenios colectivos de trabajo entre 1948 y 1994 / Evolution of the working conditions in the steel industry in Argentina. An analysis based on the collective labor agreements between 1948 and 1994, Revista Izquierdas, 27, abril 2016, ISSN 0718-5049, pp. 87-104

producción: "Establece mediante los tiempos observados y registrados el premio a la producción individual y/o colectivo del personal obrero." ${ }^{40}$ Esto resulta un indicio de que el premio a la productividad se habría estado implementado en la rama, más allá de que no estuviera estipulado por convenio. Lo que la eliminación del artículo 83 habilitaba era la posibilidad de que el gremio se opusiera a esta forma de incentivación y, por lo tanto, realizara medidas de fuerza.

En 1994, se incorpora en el convenio, mediante un acta acuerdo, el premio a la productividad en la rama automotriz, que incluía tanto a los obreros de las terminales como de las fábricas autopartistas afiliados a la UOM. ${ }^{41}$ Allí se estipula una forma de estándar para medir el premio basada en objetivos de aumento de la producción de un $10 \%$ anual. ${ }^{42}$

\section{Actividad gremial}

La actividad gremial en los lugares de trabajo aparece reglamentada desde el convenio de 1948. Básicamente, se trata de normativa relativa a las comisiones internas y los cuerpos de delgados, que constituían la representación sindical en los establecimientos. La existencia de estos organismos había sido legalizada en 1945 mediante el Decreto $\mathrm{n}^{\mathbf{0}} 23.852$, que brindaba a las asociaciones con personería gremial el derecho de "contribuir a la vigilancia en el cumplimiento de la legislación del trabajo" y a los obreros el derecho a peticionar a sus empleadores "por sí o por intermedio de sus representantes". ${ }^{43}$ El funcionamiento de estos cuerpos variaba de una rama a la otra, según los acuerdos a los que se llegara en cada sector. En la rama metalúrgica, el gremio logró frenar algunas peticiones patronales que limitaban el accionar de las comisiones internas, que en otras ramas se habían plasmado en los convenios colectivos. ${ }^{44}$ Sin embargo, ya desde el convenio de 1948, aparecen ciertas pautas que se irán modificando.

En el convenio de 1948, aparece un artículo acerca de la obligación por parte de la empresa de permitir colocar una pizarra para uso de la comisión interna para publicitar informaciones. ${ }^{45}$ También se reglamenta la formación de una Comisión de Interpretación de cada rama y una Comisión Paritaria General de la Industria, como autoridades de interpretación del convenio. La Comisión de Interpretación de cada rama debía resolver las divergencias surgidas que no pudieran ser resueltas por la Comisión de Relaciones de cada establecimiento y estaría conformada por 3 miembros de la parte patronal y 3 de la obrera

\footnotetext{
${ }^{40}$ Convención Colectiva de Trabajo no 260/75, Op. Cit., art. 3.

${ }^{41}$ Cabe aclarar que los obreros de las terminales automotrices se encuentran fragmentados en dos sindicatos: un sector mayoritario está afiliado al SMATA (Sindicato de Mecánicos y Afines del Transporte Automotor) y uno minoritario, a la UOM. En el sector autopartista, también se da está fragmentación, aunque no resulta tan claro cuál sindicato es mayoritario.

${ }^{42}$ Acuerdo, S/N, A-23, 25/08/1994, Cláusula sexta.

${ }^{43}$ Decreto n 23.852 del 2/10/1945, artículos 33 y 49.

${ }^{44}$ Marina Kabat y Ianina Harari, "Las comisiones internas bajo el peronismo clásico (Argentina 1946-1955). Conflictos en torno a su accionar y reglamentación”, en Cuadernos de Historia, n 41 , Chile, Diciembre de 2014.

${ }^{45}$ Convención Colectiva de Trabajo no 22/48, Op. Cit., art 40.
} 

convenios colectivos de trabajo entre 1948 y 1994 / Evolution of the working conditions in the steel industry in Argentina. An analysis based on the collective labor agreements between 1948 and 1994, Revista Izquierdas, 27, abril 2016, ISSN 0718-5049, pp. 87-104

y, si una de las partes lo requiere, presidida por un funcionario de la Secretaría de Trabajo y Previsión. Si no existiese acuerdo de partes en esta Comisión, la discrepancia sería elevada a la Comisión Paritaria General. Esta última estaría compuesta por un representante patronal de cada rama de la industria e igual número de representantes obreros, con sus respectivos suplentes, y presidida por un funcionario de la Secretaría de Trabajo y Previsión, con voto decisivo en caso de empate. Este mecanismo es constante a lo largo del período.

En 1951, se agrega que la pizarra sindical sólo podía utilizarse para fines gremiales y que no se podía poner inconvenientes para que el personal se acerque en horas de trabajo, "siempre que no se formen aglomeraciones"46. También en 1951 se estableció que los miembros de la Comisión Interna tuvieran permiso para realizar gestiones gremiales en el Ministerio de Trabajo y Previsión. Asimismo, se estableció la obligación de la empresa de reconocer a aquellos miembros de la comisión interna y delegados cuya designación haya sido comunicada por la UOM y a no aplicarles sanciones sin causa debidamente justificada ni cambios de horarios de trabajo o traslados sin previa comunicación a sindicato. ${ }^{47}$ Es decir, que ese año se restringe el uso de la pizarra pero se imponen ciertos derechos para los representantes sindicales.

Como vemos, la actividad de las comisiones internas y los cuerpos de delegados en la rama metalúrgica no fue restringida en los convenios firmados en los primeros gobiernos peronistas. El sindicato logró frenar la ofensiva de la patronal del sector que buscaba limitar las atribuciones de los representantes sindicales en las fábricas. Una de las principales preocupaciones de los empresarios del sector era que la función gremial de los delegados interfería con sus tareas laborales, aunque en principio de manera no alarmante. En su revista sugerían que se debía: "desarraigar el mal hábito de algunos delegados, que parecen considerar que la función es incompatible con el cumplimiento de sus deberes para con el empleador y trabajan lo menos posible o no trabajan nada."48

La cámara metalúrgica recibía frecuentemente consultas de sus socios acerca de cómo actuar frente a este tipo de situaciones. Las quejas tenían como eje el tiempo que perdían los delegados en recorrer la fábrica para hablar con los compañeros, la paralización del trabajo por conflictos menores y las reuniones periódicas. En estos casos aconsejaban prudencia en el trato con los representantes gremiales para evitar "situaciones desagradables" ${ }^{49}$ Incluso se advertía que resultaba delicado querer despedir a un obrero que se encontraba desempeñando funciones gremiales o que las hubiera desempeñado recientemente. Las empresas temían, sobre todo a la respuesta que pudieran dar del sindicato y los compañeros del delegado. Otro problema era la cantidad de trámites que realizaban los representantes gremiales. Los patrones metalúrgicos solicitaron al Ministerio de Trabajo y Previsión que se agilizaran los trámites en las audiencias de conciliación porque debían abonar jornales improductivos tanto a los obreros implicados como a la

\footnotetext{
${ }^{46}$ Convención Colectiva de Trabajo nº 97/51, Op. Cit., art. 70 y 71.

${ }^{47}$ Ibid, art. 35, 36 y 37.

${ }^{48}$ Metalurgia, $\mathrm{n}^{\mathbf{o}} 117$, abril de 1950, p. 10.

${ }^{49}$ Metalurgia, $\mathrm{n}^{\circ} 129$, mayo de 1951. p. 24.
} 

convenios colectivos de trabajo entre 1948 y 1994 / Evolution of the working conditions in the steel industry in Argentina. An analysis based on the collective labor agreements between 1948 and 1994, Revista Izquierdas, 27, abril 2016, ISSN 0718-5049, pp. 87-104

comisión interna que también asistía. Sin embargo, dado cierto vacío legal respecto a las funciones, derechos y obligaciones de las comisiones internas y delegados, los empresarios carecían de herramientas para imponer una mayor disciplina.

En todas las consultas que la cámara metalúrgica recibía respecto a cómo actuar frente a los "abusos" de los delegados, la respuesta siempre comenzaba con una queja sobre la falta de reglamentaciones. Por este motivo, comienzan a reclamar la sanción de un reglamento. En marzo de 1952, durante la negociación del convenio salarial, por presión de la parte empresaria se pactó iniciar la discusión sobre un reglamento para las comisiones internas. Como esto no se concretó, en 1954, la patronal volvió a exigir el debate de este reglamento como condición para la negociación salarial, pero tuvo que ceder frente a la negativa obrera. ${ }^{50}$

Ante este vacío, la cámara promovió acuerdos particulares en los establecimientos. ${ }^{51}$ Asimismo, insistió sobre la necesidad de imponer una reglamentación. Cuando se convocó al Congreso de la Productividad y el Bienestar Social, en 1955, presentó una ponencia sobre el reglamento para las comisiones internas. ${ }^{52} \mathrm{El}$ reglamento propuesto buscaba limitar la intervención gremial en las relaciones entre los trabajadores y la patronal. Por ejemplo, en el art. 2, se proponía que, ante la emergencia de un problema, éste debía plantearse en primera instancia a título individual y, sólo si no se resolviera el conflicto de este modo, podrían intervenir los delegados y las comisiones internas Además, se buscaba prohibir que la comisión interna tomara medidas de fuerza, estableciendo que de no alcanzarse un acuerdo la negociación debía continuar obligatoriamente en el Ministerio o en la justicia.

Art. $13^{\circ}$ - La Comisión Interna no podrá tomar de por sí ninguna determinación con respecto a los asuntos o problemas que no haya podido resolver con el empleador, debiendo en tales circunstancias recurrir al Ministerio de Trabajo y Previsión o a la Justicia en su caso. Bajo ningún concepto se podrá paralizar o alterar la normalidad del trabajo por este motivo, sin agotarse la gestión conciliatoria ante la autoridad competente u obtenerse la solución judicial que corresponda. En caso de adoptarse medidas de fuerza el empleador podrá aplicar las sanciones que hubiera lugar. ${ }^{53}$

Otra intención del proyecto era evitar la pérdida de tiempo de trabajo en asuntos gremiales y que delegados y miembros de la comisión interna tuviesen una comunicación fluida para adoptar medidas de fuerza de manera inmediata ante la aparición de un problema. Por ello, se incluía un artículo que pretendía imponer que para comunicarse entre sí, los miembros de la comisión interna, debían solicitar permiso a sus jefes de sección indicando los motivos por escrito y se prohibía que los delegados se comunicaran entre sí en horarios de trabajo. También se pretendía que los delegados atendieran los reclamos del

\footnotetext{
${ }^{50}$ Metalurgia, $\mathrm{n}^{\mathrm{o}} 162$, mayo de 1954.

${ }^{51}$ Metalurgia, $\mathrm{n}^{\circ} 156$, octubre de 1953.

${ }^{52}$ Metalurgia, $\mathrm{n}^{\circ}$ 169, enero-febrero de 1955.

${ }^{53}$ Metalurgia, $\mathrm{n}^{\circ}$ 169, enero-febrero de 1955, pp. 11-23.
} 

convenios colectivos de trabajo entre 1948 y 1994 / Evolution of the working conditions in the steel industry in Argentina. An analysis based on the collective labor agreements between 1948 and 1994, Revista Izquierdas, 27, abril 2016, ISSN 0718-5049, pp. 87-104

personal por fuera del horario de trabajo. Otros puntos salientes del proyecto era la prohibición a los miembros de la comisión interna y a los delegados de impartir órdenes relacionadas con el trabajo y la producción: “Art. 14 - Las Comisiones Internas y los delegados no podrán impartir órdenes relacionadas con el trabajo, ni oponerse a las disposiciones de la producción y ordenamiento de la producción que adopte el empleador." 54 En julio de 1955, la cámara solicita al Ministerio de Trabajo que se incorpore la reglamentación que presentaron al Congreso de la Productividad al convenio firmado ese año. Pero la propuesta de la patronal no fue aprobada.

Recién en el convenio que se firma en 1960, los empresarios logran imponer algunas de las reglamentaciones. Por ejemplo, que el representante sindical que debía ausentarse en horario laboral para atender asuntos gremiales, informara a su inmediato superior, quien debía extenderle una autorización. ${ }^{55}$ También se reglamentó la cantidad de delegados y la composición numérica de la Comisión Interna, según la cantidad de obreros del establecimiento: hasta 20 personas, corresponden dos delegados; hasta 50; tres delegados; más de 50, un delegado por cada 30 o fracción mayor a 20. Por su parte la Comisión Interna designada por el Cuerpo de Delegados debía componerse por tres miembros, si el personal iba de 20 a 50 trabajadores; por 5 miembros si la cantidad de obreros era de 50 hasta 3 mil y por 7 delegados, en caso de superar los 3 mil trabajadores. Asimismo, se estableció que las reuniones entre la comisión interna y la patronal debían ser semanales y debían labrarse actas. En cuanto a los requisitos para ser delegado, quedó asentado que era necesario contar con un año de antigüedad en la industria y seis meses en el establecimiento. ${ }^{56}$

En 1970, el limite etáreo disminuye a 21 y en 1975 a 18. De esta forma la postulación para delegado deja de ser tan restrictiva hacia los trabajadores más jóvenes, teniendo en cuenta que en muchas fábricas metalúrgicas regía el trabajo de aprendices menores de 18 años, como el caso de las escuelas técnicas de algunas fábricas.

\section{Hacia una periodización}

Como mencionamos al comienzo, los convenios colectivos pueden aportar al establecimiento de una periodización de los momentos históricos en los que se produjo un avance o retroceso de los derechos de los trabajadores.

En la Argentina, se ha generado recientemente un debate en torno al período que va del '59 al '69. Existía cierto consenso historiográfico acerca de la caracterización de la década del '60 como un momento de pérdida de derechos, tras la derrota de la resistencia peronista en $1959 .{ }^{57}$ Este ciclo sería revertido a partir de 1969 , con la reactivación de la

\footnotetext{
${ }^{54}$ Idem.

${ }^{55}$ Convención Colectiva de Trabajo no $55 / 60$, Op. Cit., art. 82

${ }^{56}$ Convención Colectiva de Trabajo $n^{\circ} 55 / 60$, art. 82.

${ }^{57}$ James, op. cit.
} 

convenios colectivos de trabajo entre 1948 y 1994 / Evolution of the working conditions in the steel industry in Argentina. An analysis based on the collective labor agreements between 1948 and 1994, Revista Izquierdas, 27, abril 2016, ISSN 0718-5049, pp. 87-104

lucha obrera. Esta periodización fue cuestionada recientemente mediante la hipótesis de que no nos encontraríamos ante un momento de retroceso de las conquistas obreras. ${ }^{58}$

Uno de los elementos de este debate es la naturaleza del convenio metalúrgico de 1960. El mismo es tomado por James como un indicador del avance patronal en torno a sus reclamos por una mayor productividad. En cambio, Schneider cuestiona esta visión y relativiza la importancia de la introducción del artículo 83, citado más arriba, acerca del salario a destajo. El autor plantea que dicho artículo no sólo resulta ambiguo sino que además, no es posible deducir su aplicación.

Aunque el artículo introduce -de manera ambigua- la posibilidad de alterar los niveles de producción, no se puede deducir que, efectivamente, ésta haya sido aplicada. Más aún, alterada a favor del capital y que, por ende, eso implique una 'profunda derrota de la clase obrera'. En nuestra opinión, los intentos por incrementar los índices de productividad tuvieron su resolución no en una disposición legal, sino en la lucha de clases. $^{59}$

Si bien compartimos la afirmación de que la aplicación de esquemas de incentivos es determinada por las relaciones de fuerza entre las clases, creemos que el convenio es un reflejo no inmediato de aquellas y constituye el corolario de una derrota. Este artículo establece una garantía legal para la patronal de que el sindicato no se opondría a la aplicación de este tipo de medidas $y$, en ese sentido, consideramos que no existe ambigüedad en el mismo. Por esta razón, acordamos con la afirmación de James acerca de que la definición de pautas de productividad pasó a ser prerrogativa exclusiva de la patronal. ${ }^{60}$ Por otro lado, en cuanto a la efectiva aplicación de pautas de productividad, hemos visto que las mismas ya eran utilizadas con anterioridad a la firma del convenio y que eran combatidas por los obreros. Lo que el gremio expresa en esta cláusula es un compromiso legal de que no realizará ninguna medida en contra de estas pautas. Es llamativo, en ese sentido, que este artículo desaparezca del convenio de 1975, tras el alza de las luchas obreras, dentro de las cuales los obreros metalúrgicos han tenido un importante desempeño. ${ }^{61}$

Otro de los puntos que analiza Schneider es la reglamentación sobre la organización gremial que, según él, se habría introducido en 1960, ya que no figura en el convenio de

\footnotetext{
58 Alejandro Schneider, Los compañeros. Trabajadores, izquierda y peronismo 1955-1973, Buenos Aires, Imago Mundi, 2005.

${ }^{59}$ Schneider, op. cit., 148.

${ }^{60}$ Daniel James, "Racionalización y respuesta de la clase obrera: contexto y limitaciones de la actividad gremial en la Argentina", Juan Carlos Torre (comp.), La formación del sindicalismo peronista, Buenos Aires, Legasa, 1998.

${ }^{61}$ Agustín Santella y Andrea Andujar, El Perón de la fábrica éramos nosotros: las luchas de Villa Constitución 1970-1976. Buenos Aires, Desde el Subte Editoriales, 2007; Héctor Löbbe, La guerrilla fabril. Clase obrera e izquierda en la Coordinadora de Zona Norte del Gran Buenos Aires (1975 - 1976), Buenos Aires, Ediciones RyR, 2007.
} 
Ianina Harari, Evolución de las condiciones de trabajo en la industria metalúrgica argentina. Un análisis a partir de los convenios colectivos de trabajo entre 1948 y 1994 / Evolution of the working conditions in the steel industry in Argentina. An analysis based on the collective labor agreements between 1948 and 1994, Revista Izquierdas, 27, abril 2016, ISSN 0718-5049, pp. 87-104

1948. ${ }^{62}$ Sin embargo como hemos visto, gran parte de las mismas eran preexistentes, dado que ya aparecían en el convenio de 1951. La única que se agrega en 1960 es la referida a la composición numérica del cuerpo de delegados y la comisión interna, así como los requisitos para poder ser electo delegado, como hemos desarrollado previamente. No parece deducirse a priori de estos puntos la mayor o menor limitación a la actividad de las comisiones internas. En todo caso, esta reglamentación de la actividad no parece ser una completa novedad del convenio del '60.

Por fuera de estos puntos, hay otros problemas que deben ser tenidos en cuenta a la hora de analizar el convenio del '60 como indicador de la derrota y el del '75 como indicador de una relación de fuerzas más favorables a los obreros. En el convenio del '60 aparece una serie de artículos que trascienden estrictamente el problema de la productividad pero que resultan perjudiciales para los obreros, como la cuestión del horario de trabajo y el ausentismo. El ausentismo era uno de los puntos sobre los cuales el sector empresario reclamaba solución desde el Congreso de la Productividad bajo el segundo gobierno peronista. En este sentido, la inclusión de una serie de restricciones para el goce de sueldo por enfermedad, a las licencias por enfermedad de familiares e incluso para el pedido de licencias sin goce de sueldo apuntaban a restringir el ausentismo. En cuanto al horario de trabajo, el artículo sobre la obligatoriedad de cumplir por completo la jornada laboral, parece expresar que la misma no era respetada. Estas cuestiones, sumadas a las ya analizadas sobre la cuestión de la productividad tienden a buscar la imposición de una mayor disciplina laboral. Esto es explícitamente expresado por la representación gremial en el mismo convenio: "La representación sindical puso de relieve un amplio ánimo de cooperación, para lograr un acuerdo que permitirá una mayor productividad fabril, con el ordenamiento interno de las empresas, tanto disciplinaria como técnicamente, única salida que posibilitará el mejoramiento económico de los trabajadores". ${ }^{3}$

En cuanto al convenio de 1975, parece tender a alivianar las condiciones para los obreros. Además de la eliminación del artículo que compromete al sindicato a no oponerse a cualquier modificación de las pautas productivas, se establecen otros puntos favorables. En cuanto a las condiciones de trabajo generales para la rama, un elemento a destacar es la eliminación de la obligatoriedad por parte de los obreros de tener posesión de ciertas herramientas como el calibre así como la adjudicación de la responsabilidad por el abastecimiento y funcionamiento de las mismas a la empresa. De esta manera el obrero no perdía una jornada de salario a causa de la falta de herramientas o por su averío. A su vez se amplía el horario de descanso para la merienda y se flexibilizan las condiciones para el goce de sueldo por licencia de enfermedad. En cuanto a los accidentes de trabajo, no resulta menor la inclusión de la condición de que pasado el año, el accidente será considerado permanente a los efectos de la indemnización. Esto implica que el monto de la misma podría aumentar considerablemente.

\footnotetext{
${ }^{62}$ Schneider, op. cit., 149. Cabe aclarar que el convenio inmediato anterior es el de 1958, pero que tiene un carácter salarial. El convenio que rige es el de 1951. Se debe distinguir entre convenios salariales y los convenios que establecen acuerdos más generales.

${ }^{63}$ Convención Colectiva de Trabajo n ${ }^{\circ} 55 / 60$, Op. Cit.
} 

convenios colectivos de trabajo entre 1948 y 1994 / Evolution of the working conditions in the steel industry in Argentina. An analysis based on the collective labor agreements between 1948 and 1994, Revista Izquierdas, 27, abril 2016, ISSN 0718-5049, pp. 87-104

El convenio firmado en 1975 no es rediscutido en su totalidad, pero sí hemos visto que en la década del '90 se impone el premio a la productividad, al menos en el sector automotriz con representación de la UOM. La inclusión de este premio fue justificada aduciendo que: "El sector automotriz enfrentó en el mes ppdo. una situación absolutamente excepcional que exigía entre otros requisitos el establecimiento de cláusulas de contenido económico y de metodologías de trabajo indispensables para encarar nuevos planes de inversión, en consonancia con el mantenimiento de los niveles de empleo" ${ }^{\text {"64 }}$.

Es decir, que el sindicato aceptó, a diferencia de otros momentos, el sometimiento de los trabajadores de la empresas automotrices encuadrados en la UOM a pautas de trabajo y de salario por productividad, que implican la obligación de trabajar de manera más intensa para obtener un mejor salario. Si bien estas pautas seguramente existían de hecho en varias empresas, en 1994 aparecen estipuladas por primera vez a nivel de un convenio colectivo, lo cual otorga una mayor jerarquía legal. Pero como hemos visto, el avance sobre los derechos obreros no fue una novedad de la década del '90.

La trayectoria histórica que señalamos para el caso metalúrgico no resulta excepcional. En un artículo colectivo, hemos analizado comparativamente la evolución de los convenios en nueve ramas, lo cual da cuenta de que existe una tendencia general a la degradación de las condiciones de trabajo obreras fijadas en los convenios, si bien la negociación en cada rama contiene particularidades que arrojan resultados más o menos favorables según la capacidad de negociación de cada gremio. ${ }^{65}$ Por ejemplo, las clausulas por productividad logran imponerse en la década del 60 en ramas como la del calzado, curtiembre, automotriz (en la empresa Mercedes Benz, donde había sido eliminada anteriormente) o textiles. Asimismo, se verifican pautas más desfavorables a los trabajadores en lo referente a jornada laboral y clasificación de categorías. En los casos analizados se observa que las demandas patronales son similares y datan desde el período de los gobiernos peronistas. Con diferentes temporalidades, los reclamos empresarios comienzan a ser satisfechos durante la década del 60, profundizándose en mayor o menor medida en las décadas posteriores.

\section{Conclusiones}

Hemos analizado los convenios firmados en la rama metalúrgica entre 1948 y 1994 a partir de tres ejes. No pretendemos con ellos agotar todos los puntos que pueden ser examinados en los convenios, pero sí tomar algunos de los más relevantes. El primero de ellos, acerca de las condiciones de trabajo. Allí no se observa una rigidez completa en torno a las tareas que le corresponde al personal según su categoría, ya que se acepta la posibilidad de realizar otras tareas, pero sí se establece el pago de los adicionales correspondientes. Los principales cambios en este campo se refieren a advertencia en 1960 acerca de la obligatoriedad de cumplir la jornada laboral completa. En 1975 un cambio importante se da

\footnotetext{
${ }^{64}$ Ibid, p. 7.

${ }^{65}$ Marina Kabat, Ianina Harari, Julia Egan, Rocío Fernández, Sebastián Cominiello, Roberto Muñoz, Ezequiel Murmis: Op. Cit.
} 

convenios colectivos de trabajo entre 1948 y 1994 / Evolution of the working conditions in the steel industry in Argentina. An analysis based on the collective labor agreements between 1948 and 1994, Revista Izquierdas, 27, abril 2016, ISSN 0718-5049, pp. 87-104

cuando la posesión de ciertas herramientas para determinadas tareas ya no es obligación del obrero sino de la empresa, que debe proveérselas, desligando al obrero de toda responsabilidad por su averío. Asimismo ese año se establece el lapso de un año para declarar una incapacidad por accidente como permanente.

En cuanto a las licencias, hemos notado que el convenio de 1960 establece restricciones para el goce de licencias, con o sin goce de salario. Estas restricciones serán flexibilizadas hacia 1975, en especial las relativas a ausencia por enfermedad y al pedido de licencias sin goce de sueldo.

Respecto a la cuestión de la productividad hemos visto que las pautas relacionadas con este sistema existían en la rama, aunque el convenio no lo regulaba. En 1960 se establece en el convenio que el sindicato no se opondría a este tipo de pautas, lo cual dejaba la vía libre a la patronal para utilizarlas. Este artículo será eliminado del convenio en 1975. En 1994, observamos que se incorpora al convenio un premio a la producción para los obreros de la rama automotriz.

En relación a la actividad gremial, notamos que la misma aparece regulada ya desde 1948. Esta regulación fue acrecentada en 1951 y luego en 1960 se impusieron algunos elementos más como el número de delegados por tamaño de establecimiento y las condiciones que un obrero debía cumplir para ser delegado, de las cuales la edad será reducida en 1975 a 18 años.

Por último hemos intentado establecer una relación entre los distintos convenios con distintos períodos políticos, que implicaron relaciones de fuerzas cambiantes, las cuales se reflejaron de manera no necesariamente inmediata en los convenios colectivos. En ese sentido, consideramos que la década de 1960 fue un período de pérdida de conquistas laborales, lo cual ve reflejado no sólo por el artículo referido al trabajo a destajo sino además, por otra serie de condiciones desfavorables para los trabajadores que tendían a imponer una mayor disciplina fabril, como los referidos a las licencias. Asimismo, creemos que el convenio de 1975 refleja mejores condiciones para los obreros, mientras que en los '90 se incorporan pautas de productividad desfavorables a los obreros. Entendemos que estos cambios son consecuencia de los cambios en las correlaciones de fuerzas entre obreros y empresarios que no dependen necesariamente del carácter democrático o dictatorial de los gobiernos. En este sentido, pueden actuar como indicadores parciales del avance o retroceso de la lucha de los trabajadores por conseguir mejores condiciones laborales.

\section{Bibliografía}

Bitrán, Rafel, El congreso de la Productividad, Buenos Aires, El bloque editorial, 1994. De la Garza Toledo, Enrique, "La flexibilidad del trabajo en América Latina", Enrique De la Garza Toledo, Tratado Latinoamericanos de Sociología del Trabajo, México, Siglo XXI, 2000. 
Ianina Harari, Evolución de las condiciones de trabajo en la industria metalúrgica argentina. Un análisis a partir de los convenios colectivos de trabajo entre 1948 y 1994 / Evolution of the working conditions in the steel industry in Argentina. An analysis based on the collective labor agreements between 1948 and 1994, Revista Izquierdas, 27, abril 2016, ISSN 0718-5049, pp. 87-104

Gaudio, Ricardo y Pilone, Jorge, "El desarrollo de la negociación colectiva durante la etapa de modernización industrial en la Argentina. 1935-1943”, Desarrollo Económico, Vol. 23, n ${ }^{\circ}$ 90, julio-septiembre de 1983. Levaggi, Abelardo, "Historia del derecho argentino del trabajo (1800-2000)", Iushistoria, Buenos Aires, Universidad del Salvador, nº 3, setiembre de 2006.

James, Daniel, "Racionalización y respuesta de la clase obrera: contexto y limitaciones de la actividad gremial en la Argentina", Juan Carlos Torre (comp.), La formación del sindicalismo peronista, Buenos Aires, Legasa, 1998.

James, Daniel, Resistencia e Integración: el peronismo y la clase trabajadora argentina: 1946-1976, Buenos Aires, Sudamericana, 1990.

Kabat, Marina y Ianina Harari, "Las comisiones internas bajo el peronismo clásico (Argentina 1946-1955). Conflictos en torno a su accionar y reglamentación”, en Cuadernos de Historia, $\mathrm{n}^{\circ}$ 41, Chile, Diciembre de 2014.

Kabat, Marina, Ianina Harari, Julia Egan, Rocío Fernández, Sebastián Cominiello, Roberto Muñoz, Ezequiel Murmis, “Avances y retrocesos de la flexibilidad laboral en la Argentina. Aportes para una comparación de las trayectorias históricas de distintas ramas de actividad", Mundos do Trabalho, vol. 6, no 12, Brasil, julio-diciembre de 2014.

Löbbe, Héctor, La guerrilla fabril. Clase obrera e izquierda en la Coordinadora de Zona Norte del Gran Buenos Aires (1975 - 1976), Buenos Aires, Ediciones RyR, 2007.

Marcos Giménez Zapiola y Carlos Leguisamon, "La concertación en 1955. El Congreso de la Productividad". Juan Carlos Torre (comp.), La formación del sindicalismo peronista, Buenos Aires, Legasa. 1980.

Santella, Agustín y Andrea Andujar, El Perón de la fábrica éramos nosotros: las luchas de Villa Constitución 1970-1976. Buenos Aires, Desde el Subte Editoriales, 2007.

Schiavi, Marcos, "Ser o no ser Clase obrera y gobierno peronista: el caso de la huelga metalúrgica de 1954", Theomai, no 18, 2008.

Schneider, Alejandro, Los compañeros. Trabajadores, izquierda y peronismo 1955-1973, Buenos Aires, Imago Mundi, 2005.

Simonassi, Silvia y Laura Badaloni, "Prácticas sociales y políticas estatales en dos coyunturas de conflictividad laboral: estado, industriales y trabajadores metalúrgicos durante el primer peronismo", Segundas Jornadas de Historia Regional Comparada, 2005.

\section{Documentos}

Acuerdo, S/N, A-23, 25/08/1994.

Boletín de la Bolsa de Comercio $\mathrm{n}^{\circ}$ 2847, 30/11/1959.

Convención Colectiva de Trabajo n ${ }^{\circ}$ 97/70, Ministerio de Economía y Trabajo, Secretaría de Estado de Trabajo, 18 de marzo de 1970.

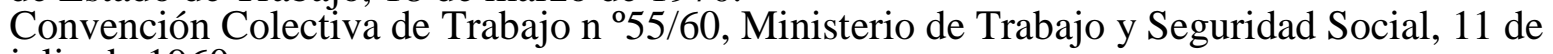
julio de 1960.

Convención Colectiva de Trabajo no 260/75, Ministerio de Trabajo, Buenos Aires, 24 de julio de 1975 . 
Ianina Harari, Evolución de las condiciones de trabajo en la industria metalúrgica argentina. Un análisis a partir de los convenios colectivos de trabajo entre 1948 y 1994 / Evolution of the working conditions in the steel industry in Argentina. An analysis based on the collective labor agreements between 1948 and 1994, Revista Izquierdas, 27, abril 2016, ISSN 0718-5049, pp. 87-104

Convención Colectiva de Trabajo no 97/51, Ministerio de Trabajo y Previsión, Dirección Nacional de Trabajo y Acción Social Directa, Registro General de Convenios y Laudos, 1951.

Convención Colectiva $n^{\circ}$ 22/48, Ministerio de Trabajo y Previsión, Dirección Nacional de Trabajo y Acción Social Directa, Registro General de Convenios y Laudos, Buenos Aires, 2 de marzo de 1948.

Decreto $\mathrm{n}^{\circ} 23.852$ del 2/10/1945.

Metalurgia, $\mathrm{n}^{\circ} 117$, abril de 1950.

Metalurgia, $\mathrm{n}^{\mathrm{o}} 129$, mayo de 1951

Metalurgia, $\mathrm{n}^{\mathrm{o}} 156$, octubre de 1953.

Metalurgia, $\mathrm{n}^{\circ} 162$, mayo de 1954.

Metalurgia, $\mathrm{n}^{\mathrm{o}} 169$, enero-febrero de 1955.

Metalurgia, $\mathrm{n}^{\circ} 169$, enero-febrero de 1955.

Siam Di Tella: Memoria y Balance General del ejercicio vencido al 30/4/1959, en Boletín de la Bolsa de Comercio no 2846, 23/11/1959 